\title{
Social Movements Facing the Processes of Globalization: Beyond the Paradigms of Class and Identity
}

\author{
Veronica Alfaro, University of Guadalajara
}

\section{New social movements as result of a new socioeconomic order}

In our era, the process of globalization is not the cause of a different socioeconomic order, but rather is a different order in itself. This statement does not pretend to oversimplify the various processes that make globalization; nor does it take for granted assumptions about the social nature of the contemporary world. Social change must be understood in a broad, dynamic sense. Change, as a social process, is obviously linked to structural and material changes, but also to superstructural events that have to do with flows of information, technology, media, culture, and politics. The acceleration of those flows implies a reordering not only of economy and world politics, but also a reinterpretation of each individual's lifestyle.

That said, although the process of globalization has generated some positive outcomes, more often than not it has posed serious problems for some groups in the crossroads of unequal social change. Most often, the south, the rural, and the underdeveloped sectors find it more difficult to keep the pace of economic integration and liberalization. This essay focuses on a particular expression of globalization and regionalization that entails social, political, cultural and economic dimensions: social movements. Over recent decades, the impact of global and regional changes on local communities has often generated movements in opposition and protest. Transnational corporations, industries, and financial institutions are seen as the triggers of changes that affect national and regional economies, policies and individual lifestyles, marginalizing some sectors of population in their pursuit of economic profits.

If it is true that social movements are nothing new, what is interesting is that their form and claims have become an inherent expression of the discontents of globalization and regionalization processes. But, why is it that movements now seem to go beyond class 
and identity claims? I will argue that current social movements are not necessarily articulated only in terms of class struggle—as the major labor movements were for the last two centuries. Neither do they articulate their protests only in terms of identity and recognition—such as women's movements did in the 1960s. Social movements are now most commonly organized around a discourse that combines those two dimensions.

Contemporary social movements are expanding from the structural economic and industrial system (and thus abandoning the form of traditional class struggles) to cultural and identity grounds. New social movements are now seen more and more as symbolic challengers, because power - that affects everyday life and tries to manipulate and give social meaning to things-is being contested by individuals in both the public and private spheres. Thus movements have a more symbolic function: they are a new kind of media, fighting for symbolic and cultural stakes, and for a different meaning and orientation of social action. However, constructing a collective identity within a social movement is not definitive. A movement's identity is constructed on an everyday basis, and within the process of globalization, the contact and social interaction with others -with the other, which allows the definition of one's own identity—is not only possible but also necessary.

This paper considers the Zapatista rebellion in Chiapas as an empirical approach to social movements expanding from regional, local mobilizations and discourse, to more global oriented contentious activities. I argue that the Zapatista movement's identity in 1994 was quite different from the one it has now: the Ejército Zapatista de Liberación Nacional (EZLN, or Zapatista National Liberation Army) discourse has been transformed, from having an ethnic, communitarian point of view to a more global or transnational oriented vision. The Zapatistas' globally constructed image is now not only that of a particular, local revolution, but also reflects a pretended universalism in their political proposal: a reordering of the necessary and irreversible global structural transformation. The movements' demands are thus an aspect of the actual process of configuring an 'alternative revolution of global scale', as a rejection of the new political, social and economic order, both at the local and global levels. 
In the case of Zapatismo, the form of the movement has become a message, a symbolic challenge to the dominant global patterns that redefine the meaning of social action for the local society—namely, neoliberal policies. In other words, what is new-although not exclusive to Zapatismo as a social movement-is that what is at stake in its discourse is the production of humanity, related to the transnational nature and effects of globalization and the interdependence of the world system.

\section{Class, identity and social movement theories}

This section is an overview of some of the theoretical frameworks that deal with the complexity of social movements within the context of globalization and regionalization. There is no single paradigm that can take into account the amount of historical, political, and global conditions and interactions necessary to the comprehension of such phenomena. The goal here is not to conscript Zapatismo in any given paradigm, but rather to use it as a starting point to compare some of the strengths and weaknesses of the Resource Mobilization and Rational Choice approaches, as well as the European paradigm of New Social Movements, and the American school of Political Opportunity Structure.

To analyze the social movements that are now inserted in the logics of globalization/regionalization, with regard to a local and — at the same time global— movement, we must transcend the theoretical dichotomies and ideological battles between paradigms. Going beyond the divisions and polarized conflict would integrate the different approaches' emphasis on the role of structural processes, political opportunities and collective identity that are crucial to understanding contemporary movements.

The Resource Mobilization (RM) theoretical framework and its variants study the concept of political opportunities and the relationship of social movements to the statesupported by, among other social scientists, Charles Tilly (1981; 1995) and Douglas McAdam (1995). These approaches focus on the micro mobilization of activists, in how 
networks are used for recruitment through the use of incentives, the conditions under which people participate, as well as tactics for fund-raising. This paradigm also studies the free rider effect, by introducing the concept of costs and alternatives. Such an approach focuses on inter-organizational relations, coalitional work, organizational conflict and internal divisions.

At first sight, the American RM model, with its strong dose of Rational Choice theoretical foundation, seems an inappropriate tool for analyzing the Zapatista movement. It does not take into account the role of social solidarity, motivation or the role of meanings and culture. Those cultural creations are nevertheless part of a symbolic discourse that is fundamental for social movements. How these symbols and their meanings change through history is not studied by the resource mobilization theory, which does not have any linguistic, cognitive or emotive elements to analyze meaning systems.

Moreover, though RM may be useful for explaining cycles of collective action and contentious repertoires, it does not consider the particular orientation of every historical period. However useful it may be for the analysis of globally networked movements, the RM approach does not take account of values and ideology. Other analysis of movements take motivational meanings into account, considering their ends and values as moral commitments of individuals and groups. Behaviors affirm values, and social movements are committed to such moral principles that promote alternative lifestyles. This fact explains why new social movements that base their analysis in consciousness and class conflicts are studied out of RM framework, in the manner of the European theorists Alain Touraine and Manuel Castells.

In the same vein, but framed within the American school of Social Movements, are some elements of the paradigm of Political Opportunity Structure (POS), which are useful to analyze the opening of spaces for anti-globalization collective mobilizations that are 'clustered' around a set of protests concerning social change. Sidney Tarrow, working within this theoretical stream, argues that the base of all social movements, protests and 
revolutions is contentious collective action (Tarrow 1998). His main argument is that changes in political opportunities and constrains create the most important incentives for initiating phases or cycles of contention. Those actions create opportunities for the original early insurgents, but also for latecomers and eventually for the opponents and power holders.

Contentious movements, according to Tarrow`s view, emerge when people respond, in a rational way, to the opportunities that lower the costs of collective action, reveal potential allies, show the vulnerable points of elites, and trigger social networks and collective identities into action around a common purpose. Once triggered, opportunities produce a cascade of information and incentives for new movement organizations.

In short, the POS approach analyzes political opportunities along five structural elements: a) the opening of access to participation for new social actors -because 'rational people' do not attack when opportunities are closed; b) the instability and uncertainty of political alignments; c) conflicts within and among elites; d) actions of influential allies within the political system; e) the degree of repression or facilitation of state policies to oppositional movements. In other words, the POS model is focused on when and how contention broadens into general cycles and in the phases that characterize the parabolic 'life' of contentious cycles, that can be characterized as follows: First of all, there is a conflict that is diffused to members of the same group whose identities are activated by new opportunities and threats. Early risers trigger a variety of processes of diffusion, extension, imitation and reaction among other groups. Secondly, new weapons of protest and contention (repertoires) are fashioned. Third, cycles of contention make use of old organizations and stimulate the creation of new ones. Finally, contentious cycles produce information flows and political attention that increase the interaction among challengers and challenged.

It may seem that the Zapatistas were, at one point, part of a contentious cycle of antiglobalization movements around the world. However, the weakness of the POS paradigm is the argument that contention is more closely related to opportunities for collective 
action than to social or economic factors -that are crucial to understand the emerging not only of Zapatismo, but also of other movements.

On the other side of the spectrum of social movements' theories is the identity-oriented paradigm (Melucci 1995). The role of collective identity in the analysis of contemporary social movements is a tool to explain the relations between behavior and meaning, as well as between objective conditions -such as history, economy an social changes- and subjective motives and orientations.

The use identity as an analytical tool allows explanation of how individual social actors become a collectivity and recognize themselves as part of one; how they maintain this identity over time; how collective action makes sense for the participants of a social movement; and whether the meaning of collective action derives from structural preconditions or from other individual motivations.

By trying to bridge the emphasis on identity and the sociopolitical structures of the former models, some elements of the European paradigm of New Social Movements are helpful to interpreting contemporary struggles against hegemonic global structures. For instance, Alain Touraine's approach to social movements is interesting because it emphasizes the power of civil society, the autonomy of social movements vis-à-vis the state, and the emergency of collective identities that are not subject only to class frontiers but are united against a broad hegemonic system. It must be recognized, however, that Touraine's European paradigm is based on Western assumptions about state formation, democracy, modernity and sociohistorical contexts that cannot be applied to Latin American structures. But, to this point, there are few theories that take into account the complexity of social movements in the historical crossroads of social models.

Touraine has a particular view of the societal model that corresponds to the era of globalization and regionalization processes. His sociology of action maintains that in the post-industrial or late-modern societies we are living in, or, as he puts it, in programmed societies, class domination consists in managing the production and data, ensuring the 
control of supplies and organizing social life (Touraine 1981). Therefore, a certain type of technocracy rules the new social order, and resistance to its domination cannot be limited to a particular sphere. New defenses against such apparatus of domination are carried out in support of a population's right to choose its kind of life and support its own political potential. Social movements, for Touraine, are a combination of three principles: identity, opposition and totality -or identity, adversary and societal goal, in Castells' later interpretation. Movements, still viewed as manifestations of class struggle, penetrate historicity and criticize old traditions, producing an ideology, a representation of their social relations. In other words, they become identified with the stakes of the struggle and historicity itself.

The action of social movements is thus a class action, directed against a true adversary. But it is not necessarily directed against the state and is not always a traditional political action contesting state power-as we have seen from the protests against the World Trade Organization in Seattle, Prague, New York. Contemporary social movements struggle more and more for the social control of historicity: that is, for the control of the cultural orientations by which a society's relationships are organized. In other words, what we have now, against the concentration of power and the penetration of decisionmaking apparatuses into all aspects of social and cultural life, are new social movements that take as their main objective not the conquest and transformation of the state, but the defense of the individual, of interpersonal relations, of small groups and minorities, of differences and alternatives, against a centralized power. The activity and discourse of the EZLN in recent years expresses this defense of alternative lifestyles and the right to be different.

In this context, we are seeing a violent rejection of a neoliberal, quantitative conception of human needs, a rejection that takes the form of an appeal to deep, fundamental (sometimes fundamentalist) and natural needs. These notions are indicative of a will to oppose another mode of life and other preferences to the technocratic modeling of demand. Therefore, new social movements oppose social nominations in the name of the only thing that may yet escape it: nature. In what Touraine calls 'programmed society', 
the field of social struggles is the social actor in any role -it is the human being as living being (Touraine 1988). Today's society is therefore a society of dynamic protest, of imagination and utopia, because is traversed by the conflict of the logic of power and programming, versus creativity and alternative ways of life. ${ }^{1}$

It must be recognized that the European approach has been more popular in Latin America, because it emphasizes the role civil society, the autonomy of SM vis-à-vis the state, and the emergence of non-class identities. However, all those existing paradigms are built on Western assumptions about modernity, democracy, citizenship, state formation and specific historical experiences. Latin American politics and society differ greatly from those of developed Western countries. Thus, there is still a need for a specific approach that could be able to grasp the complexity of their particular movements, from the role of culture and identity to structural conditions and class interactions.

\section{The case of Zapatismo: from a local to a global movement}

The construction and use of discourses by social movements plays an important and positive role in challenging relations and structures of power, both in respect of concentrated sites of power and in the way that power is embedded in everyday social relations. Following Castells' argument that social movements 'are what they say they are', an analysis of the Zapatista discourse throws a light on several issues: the way in which they construct their own collective identity, solidarity and collective action, and what pretends to be the 'newness' of the movement (Castells 1997, 70). Moreover, the EZLN discourse establishes causal relationships between the movement's practices and values, and the social processes to which they are associated: globalization and regionalization.

According to its own discourse, what is new in Zapatismo? What makes this movement different from other contemporary movements based in ethnic nationalism, or from other mobilizations against globalization and neoliberalism? I would say that as actors,

\footnotetext{
${ }^{1}$ About the role of imagination in the construction of the subject in late modernity, see Appadurai (2000).
} 
Zapatistas aim to create public spaces in social arenas for the affirmation of their identity and demands against modes of old and new domination, just as other movements around the world do. What makes their approach somewhat different from traditional movements, is the plurality of political actors and action within civil society that are involved and viewed increasingly not as means but as ends in themselves. In other words, part of what is new in Zapatismo is the claim that a global civil society is expanding, and has become the indispensable terrain on which social actors organize and mobilize. Zapatistas pose a challenge in two ways: one, by questioning public sites of traditional power; and two, in the way that symbolic power is embedded in everyday social relations. On the one hand, they combine instrumental demands: political, economic or social. On the other hand, they have an expressive dimension oriented towards norms, values, identities and lifestyles.

Alberto Melucci (supporting the identity-oriented paradigm) and Alain Touraine agree that social movements are expanding from the economic and industrial system to cultural and identity grounds. New movements are now seen as symbolic challengers, because power that affects everyday life and tries to manipulate and give a meaning to things, is currently being contested by them. Therefore, the function of actors in conflicts is to 'reveal' to the states and to announce to society that certain problems exist. Movements, as movement networks or areas, have a symbolic function: they are a new kind of media, fighting for symbolic and cultural stakes, and for a different meaning and orientation of social action -what Touraine calls 'historicity'.

In the case of a movement such as Zapatismo, the form of the movement has become a message. In the same way that in the global village, 'the medium is the message', social movements in the era of globalization are now a symbolic challenge to the dominant patterns that redefine the meaning of social action for the whole society. ${ }^{2}$ In other words, what is new of Zapatismo as a social movement, is that according to its discourse, what is

\footnotetext{
${ }^{2}$ The global village, however, must not be understood as a mediated process of cultural homogenization and consensus at a global level. On the contrary, it is about the social relations that are proper of this age: individuals, extending themselves through media, are in touch with a diversity of other individuals and communities. The first in proposing this idea was Marshall McLuhan (1964).
} 
at stake now is the production of humanity, being related to the transnational nature and effects of globalization and the interdependence of the world system.

As I noted earlier, the construction of identity is never definitive. In order to exist and resist, a movement's identity has to be constructed on an everyday basis. The Zapatista identity in 1994 was quite different from the one they have now: it has notoriously broadened. It is clear that Zapatistas’ identity has evolved through their years of public struggle-its discourse has transformed, first from having an ethnic, communitarian point of view to a more global, or transnational oriented vision, and lately they seem to have completed the circle back to a local movement.

The public mediated Zapatista uprising coincided with the implementation of NAFTA in 1994. But, though some activists relate the Zapatismo with a direct critique to the politics of neoliberalism and globalization, the movement's origins were quite different: first, early Zapatistas were a clearly local movement that later on gradually changed their discourse to a critique to the forms and politics of globalization. If it is true that at the beginning there was no 'timing' of the movement to coincide with the entrance of the NAFTA in January $1^{\text {st }} 1994$, it must be said that this particular date became a symbol of the oppression to the poor, as a result of the neoliberal policies that global economy had been imposing on the country since the 1980s, when Mexico entered the GATT and began to accede to the policies of the IMF and the World Bank. What early Zapatistas did was to take advantage, as Tarrow would say, of the political opportunity that resulted from a diversity of factors, which included local politics, as well as the 'democratic transition’ that Mexico was living at the beginning of the 1990s.

The transition of the Zapatista movement, from local to national and then international movement, is reflected in its discourse and rhetoric, which have continually incorporated a diversity of social demands. If in 1994 the EZLN communiqués 'Declarations of the Lancandona Rainforest' were a direct war declaration aimed to the Mexican Government and army, the discourse evolved to a constant, latent presence in the media with pacific, democratic messages adapted to very different audiences and demands. Women, children, 
the elderly, the young, indigenous peoples, ecologists, homosexuals, HIV positives, artists, intellectuals, farmers, union workers, students, NGO’s and other social actors were all addressed by EZLN's communications strategy.

At first, in the Zapatista indigenous rights stage of discourse, the most important statements were the demands to recognize the particularities of indigenous groups and their rights to autonomy and citizenship:

The indigenous problem will not have a solution if there is not a radical transformation of the national pact. The only way to incorporate with justice and dignity the indigenous to the Nation, is recognizing their own social, cultural and political organization. Their autonomy does not imply separation, but the minority integration into contemporary Mexico. (Marcos, Third Declaration) Until the Fifth Declaration of the Lacandona Rainforest, the Zapatista movement was basically a struggle for indigenous rights. The EZLN invited national civil society and independent politic and social organizations 'to fight against war and for the recognition of indigenous rights, for the transition to democracy, for an economic model that helps people and not helps itself, for a tolerant, inclusive society, for the respect to differences, for a new country where peace with justice and dignity may be for all' (Marcos, Fifth Declaration).

Later on, ecology and environmentalist concerns were incorporated to the core of the Zapatista discourse, becoming a crucial factor for the incorporation and support of other national and international actors in the movement. Zapatistas argue that indigenous communities are always among the first interested in the conservation of natural resources. They see themselves as the guardians of biodiversity, of natural 'genetic banks' as well as of their traditional knowledge. They criticize transnational companies and international research and development institutions that go into the rainforest area to investigate and patent genomes and the indigenous knowledge concerning them, and assert the necessity of indigenous peoples being recognized as part of the biodiversity of the region. In this way, they affirm:

the conservation of biodiversity, which begins with the conservation of our indigenous culture, old and new, [the] intelligent strategies of conservation which allow the gradual enrichment of the soil [and] the participatory and inclusive management of everyone in our biodiversity and our country (Marcos, With war there can be no Democracy). 
As both a global and regionally oriented movement, the Zapatistas' activities have had two dimensions of impact. At the national level and national politics, sympathizers of the movement are experimenting with new ways of expression and organization, in contradiction with the state's hegemonic forces, often developing grassroots organizations. Mobilizations of students, peasants, and NGO’s have proliferated as a result of the opening of spaces, independently of their degree of instrumental success. In Castells' words, 'the power of identity, as claimed by Marcos and the Zapatistas [...] has built bridges between the real indians, the real poor, and the educated urban sectors in search of new mobilizing utopias’ (Castells 1997, 286).

The collective mobilization of the Zapatista movement at the international level is more complex. The image of the ZLNA movement is not anymore that of a particular, local revolution, but has become a universal proposal: a social reordering of the global structural transformation of late modernity. Thus, this movement's demands are intended for inclusion in the actual process of configuring an 'alternative revolution of global scale', as a rejection of the new political, social and economic (dis)order.

Part of this intent were the 'Intergalactic encounters for humanity and against neoliberalism', that gathered people from all around the globe to discuss various forms of impact of neoliberal policies on humanity. ${ }^{3}$ Starting from the premise that 'rebels start to recognize each other, equal and different', this first Zapatista meeting against neoliberalism attempted to construct a chain of mobilization on a global scale. To this end, Marcos says:

This 'prescindible' people rebel and resist the power that wants to eliminate them. Women, children, the elderly, the young, indigenous peoples, ecologists, homosexuals, HIV positives, workers, farmers and all whom are not only in excess, but also annoy the world order and its progress. [...] Pockets of resistance are multiplying. If humanity still has survival hopes, those hopes are in the pockets formed by the excluded, the scraps, the disposable (Marcos, 'The fourth world war has begun').

\footnotetext{
3 There were delegations from Italy, Brazil, Great Britain, Paraguay, Uruguay, Chile, Philippines, Germany, Peru, Argentina, Austria, Guatemala, Belgium, Venezuela, Iran, Denmark, Nicaragua, Zaire, France, Haiti, Ecuador, Greece, Japan, Kurdistan, Ireland, Costa Rica, Puerto Rico, Cuba, Sweden, Switzerland, Holland, South Africa, Spain, Portugal, the USA ; the Basque Country, Turkey, Canada, Bolivia, Australia, Mauritania, and obviously Mexico.
} 
Gradually, Zapatistas have redefined their adversaries - their opponents-according to their own identity evolution. If, initially, the enemy was one-party rule in Mexico (embodied by the PRI) and its 'bad government', now it is globalization and neoliberalism, which embodies evil in the Zapatista discourse. To use Sub-commandant Marcos' terms, neoliberalism and its institutions are against the most elemental of human rights, having created 'an excess of human beings that are not necessary for the new global order: they don't produce, don't consume, are not credit-subjects... In sum, there are disposable’ (Marcos, 'The fourth world war has begun'). The oppressor of humanity has thus been symbolized by capitalist organizations such as the International Monetary Found, the World Bank, and transnational enterprises and corporations exploiting the labor and natural resources of Third World countries.

\section{Media and the Construction of Global Virtual Movements}

Some scholars maintain that anti-globalization or 'globaliphobic' movements resemble a pre-political movement type -such as the one described by Eric Hobsbawm, a 'Robin Hood-style' movement, aiming for material equality for the poor and a redistribution of wealth for the dispossessed (Hobsbawm 1959). I would argue that, though some of those movements might seem like primitive social movements -guerrillas and armed rebellions-, they have evolved and adapted to a global dynamic of social change, posing some interesting questions to contemporary social movements' theories and to the study of their contentious repertoires.

One of the questions that seems to be central in the historic crossroads of the 'twin processes' of globalization and regionalization is, which social movement will occupy the central position equivalent to that held by the worker's movement in industrial society, and the civil liberties movement in the market society? What kind of movement will embody now the resistance against the hegemonies resulting from a new socioeconomic order? Right now, movements such as women's rights, the ecology, indigenous peoples, and human rights appear to be becoming global social movements, meaning that they are both global in scope and have an overtly global orientation. In contemporary movements, where public opinion and mass media 'mediate' all claims, protest and contention has 
become a professional public performance. Especially, the discussion about mass media and social movements poses some interesting questions about a mediated collective action, particularly through virtual contentious networks in cyberspace. ${ }^{4}$ At first sight, it might seem that global 'virtual movements' are the new movements par excellence, the ones that inherited the banner of worker's and labor movements.

The case study for this essay demonstrates that the transnational character of Zapatismo has been constructed through media interaction and particularly through the use of cyberspace. The EZLN's success as a movement has been largely due to communication strategies; to the point that they can be called the first 'informational guerrilla' movement, conducting 'a paper and Internet' war. Actually, it is precisely the extensive use of cyberspace that allows the EZLN to diffuse information throughout the world instantly, and to create a global network of support groups and organizations. Manuel Castells considers the Zapatista rebellion to be a classical case of use of the Internet to construct an advocacy network (Castells 1997; Tarrow 1998).

In this context, the EZLN's home page on the Internet and its broad presence in cyberspace, as well as the use of print and mass media, suggests that Zapatista contentious politics are public performances. Because of the use of those global communications, Zapatismo can be seen as a kind of 'master protest frame': by dramatizing contradictions between resonant cultural values and conventional social practices, the movement links other protest identities and movements within society, adapting to its own agenda other innovative contentious action forms and new cultural items. Nonetheless it must be stressed that cyber activists construct their identities, loyalties and solidarity ties not in base of a physical presence or belonging to a particular regional space, but based on a common discourse and use of symbols. The broader the discourse, the broader the community. In a few years, Zapatistas have become a symbol

\footnotetext{
${ }^{4}$ By cyberspace, I mean not only the Internet, but the whole universe of digital networks as a world of social interaction, including its cultural and economic conflicts. Its tentative definition refers to the new media of information transmission and navigation that include but is not limited to: hypertext, the World Wide Web, interactive multimedia, video games, simulations, virtual reality, telecommunications and software. I agree with Pierre Levy in that cyberspace is an open-ended space in constant construction, that 'brings with it methods of collective perception, feeling, remembrance, working, playing and being'. See Levy (1999).
} 
for virtual communities that are not necessarily related to the original demands of the indigenous peoples: land and freedom (the original motto of Emiliano Zapata was 'tierra y libertad!')

The notion of a global network of communication - very much in the sense of a virtual community — was first envisioned by Zapatistas in the summer of 1994, during the first 'Intergalactic Meeting for Humanity and against Neoliberalism'. This time, Sub Commandant Marcos said:

We make a network of communication among all our struggles and resistances, against neoliberalism, and for humanity. This network will attempt to create channels so that words may flow to all paths that resist. It will be the medium by which distinct resistances communicate with one another. This network is not an organizing structure, nor does it have a central head or decision maker, nor does it have a central command or hierarchies. We are the network, all of us who speak and listen (Marcos 1996). ${ }^{5}$

The Internet was crucial for the organization of that first meeting and subsequent ones in Brazil and Spain. It connected activists from all around the world, very often related to other grassroots organizations and diverse struggles for diversity and anti-globalization issues. But however positive, the use of technology poses certain risks for mobilization: as Castells puts it, virtual action may replace real action. Now, writing a protest e-mail to an invisible someone, or hacking a governmental or commercial server and/or website (such as the White House, the WTO, Nike), occurs more frequently than actual physical engagement in a strike or protest situation. Cyberspace and the use of technology are instruments of contention that have changed the dynamics of some social movements, in which it is no longer necessary to 'give face', or to compromise one's body and integrity, since a virtual presence is enough. In this context, the problem of free riders within the movement reappears, with people not having a formal or physical commitment.

Virtual collective action may also imbue people with a sense of power that is not real. In Tarrow's point of view, for instance, a collective network of virtual movements is a safer, easier alternative for people: there is no contentious action, no commitment, no emotivity, and no sense of place (Tarrow 1998). In other words, without concrete action, it is difficult to measure the success of a social movement. It is true that, in the one hand,

\footnotetext{
${ }^{5}$ For a good compilation of Marcos's texts in English see Ponce de Leon (2001).
} 
cyber activist groups attempt to engage people to social reality with their advocatory emails, diffusion of news, petitions and calls for action. However, after a while, the calls to engage in real social agency loose their efficacy, and people end up deleting e-mail chains without even reading them.

For many social scientists, traditional activism, based still in the physical commitment of the body to a cause, remains paramount. Alain Touraine still insists that social movements are basically composed by 'naked bodies against an opponent, fearing to become dead naked bodies' (2001). In the case of Zapatismo, the physical involvement of the body in the movement is still a key factor for the achievement of political and democratic changes. On the one hand, it is true that the virtual Zapatista network of communication is the cause of the existence of a broad, global virtual community, and the Zapatista strategy of netwar, where they claim that 'our word is our weapon', found its perfect medium in cyberspace. ${ }^{6}$ But on the other hand, the real, local presence of the physical bodies and voices of Zapatistas (either struggling within conscripted communities in Chiapas, or marching to Mexico City) has been definitive for the consideration of their community demands and struggle to be included in a democratic political system. That is why virtual movements, though they strive to direct attention to their claims, are still regarded more as global networks of advocacy than real movements.

What is, then, the value of social movements in this late-modern 'virtual sphere'? Does cyberspace play a purely instrumental role in expressing social protest and political conflict? Or is there an actual transformation of the political into cyberspace that ultimately affects the forms and goals of movements and political actors? From what we have seen in the case of Zapatismo, the use of cyberspace has provided the material basis

Refer Sub Commandante Marcos's writings in Ponce De Leone; for sources, visit the main website of EZLN, http://www.ezln.org, and some links of the virtual community of Zapatistas:

http://www.chiapasmediaproject.org. In Italy: http://www.ipsnet.it/chiapas, http://www.ecn.org/ezln-it/

Another Italian community related to the Zapatista and other struggles: http://www.ecn.org/la.strada/ .In Ireland: http://flag.blackened.net/revolt/mexico.html .In Amsterdam:

http://www.dds.nl/ noticias/prensa/zapata/. In Australia:

http://www.geocities.com/CapitolHill/3849/zap.html. In France: http://www.zapata.com/yabasta.php3;

http://ouvaton.org/cspcl/. In the USA: http://www.geocities.com/CapitolHill/7083/,

http://www.geocities.com/CapitolHill/1364/cpage1.htm, http://zapnet.rootmedia.org/,

http://members.tripod.com/ PPLP/ 
for the movement to engage in the production of social networks. According to Castells, social change is still based upon the collective actions of individuals, and these actions are 'empowered' by the use of technology and communication tools (2001). But it is not clear whether 'the political' is affected by cyberspace in the same extent that this latter is affected by sociopolitical changes and dynamics such as global flows of money, information and cultural products.

But cyberspace and virtual movements fit within the characteristics of what has been called a new social stage: late, liquid or reflexive modernity. ${ }^{7}$ For the moment, it seems that social movements have found an appropriate medium of organization according to the rapid global flows that shape society, thus helping to envision new forms of social change in at least one way: global movements need to match the global reach of the powers that they oppose (neoliberalism, globalization and so on), and they need to achieve a global impact and visibility through media. In short, cyberspace was expected to be an instrument to achieve democracy. It is true that, on the one hand, cyberspace has in a few cases, encouraged the interaction between citizens and government. It has also been the origin of high hopes in having everyone's voices heard and thus consolidating a stronger global civil society. However, at the moment, the achievement and ideal of a global democracy is still far away.

\section{Global Movements Transcending Dichotomies}

This article has focused on how contemporary social movements are an expression of the socioeconomic changes of globalization and regionalization, and of the related individual and communitarian claims that result from them such as the right to reproduce one's own culture, identity and lifestyle. I suggested that the integration of different social movement theories’ emphases on structural processes, political opportunities and collective identities may open a new point of view to analyze recent events of movements within the overarching globalization tendencies we are experiencing. In short, this paper promotes the need to transcend the dichotomies and ideological battles between social

\footnotetext{
${ }^{7}$ For an interesting discussion on the direction and characteristics of globalization in the era of latemodernity, see Bauman (2000); also Beck, Lash \& Giddens (1994).
} 
movement theories.

In this context, I have looked at the question of what are the characteristic and claims of social movements — specifically Zapatismo. I argued that what we have now, ranged against the supranational concentration of power and the penetration of hegemonic decision-making apparatuses into social and cultural life, are movements that take as their main objective not necessarily the conquest and transformation of the state, but the symbolic defense of the individual, of interpersonal relations, of small groups and minorities (ethnic or not), and of differences with alternatives to central power.

In brief, contemporary social movements go beyond old discourses of class, and struggle to gain social control of historicity: for the control of the cultural orientations by which a society's relationships are organized. In other words, new social movements are about the right to choose one's own lifestyle.

As an expression of globalization, social movements cannot detach themselves from the processes of global flows, especially from the informational and technological ones. They are influenced by those flows, and most commonly, they try to use them to their favor. I have considered the role of new electronic technologies and media as inherent global flows that social movements can't ignore. In particular, this essay considered the use of Internet and satellite communications as new tools that are challenging old 'contentious repertoires' and proposing new, virtual ways of social agency.

I have argued that the experience of cyberspace is changing a specific form of social interaction. Electronic media is the message, and could be an experience of democratic participation in an open and global dialogue. The form of cyberactivism of Zapatismo encourages and stimulates the analysis of challenges specific to social movements; the creation of a resistance identity and solidarity, but also the exploration of how the electronic medium that movements use to spread its word has, in a way, become the message. 
All social movements that are born within a particular sociohistorical context will eventually die. It is only insofar as social movements succeed in shifting life norms and values, as a well as winning instrumental demands that they will be able to shift relations and structures of power and thus reconstruct historicity. To this moment, it seems that the more global relations hold a central position in the discourse of Zapatistas, the movement will attain a higher level, and will achieve a maximum of possible historical action.

\section{Reference list}

Appadurai, Arjun 2000, Modernity at Large. Cultural Dimensions of Globalization. Minneapolis, University of Minnesota Press.

Bauman, Zygmunt 2000, Liquid Modernity, Cambridge Polity Press.

Beck, Ulrich, Lash, Scott and Giddens, Anthony 1994, Reflexive Modernization Politics, Tradition and Aesthetics in the Modern Social Order, Standford, Stanford University Press, 1994.

Castells, Manuel, 1997, The Power of Identity. The Information Age: Economy, Society and Culture Vol II, Cambridge MA, Oxford UK, Blackwell; p. 70

—2001, Computer Networks, Civil Society and the State'; in The Internet Galaxy: Reflections on the Internet, Business and Society, Oxford, Oxford University Press.

Hobsbawm, Eric 1959, Primitive Rebels: Studies in Archaic Forms of Social Movements in the $19^{\text {th }}$ and $20^{\text {th }}$ Century, New York, Praeger Publishers, 1959.

Levy, Pierre 1999, Collective Intelligence. Mankind's emerging world in Cyberspace, Cambridge MA, Perseus Books, 1999

McAdam, Doug, 'Initiator and Spin off movements: Diffusion Processes in Protest Cycles', in) Repertoires and Cycles of Collective Action, ed. Mark Traugott, Duke University Press, 1995.

McLuhan, Marshall, Understanding Media: The Extensions of Man, Massachusetts Institute of Technology, 1964.

Marcos, Subcomandante 1996, 'Second Declaration of La Realidad for Humanity and against Neoliberalism’.

— www.ezln.org

— , N.d. 'Fifth Declaration of the Lacandon Rainforest', EZLN web page, available at www.ezln.org

— - N.d. 'The fourth world war has begun', EZLN web page, available at www.ezln.org

— - N.d. 'With war there can be no Democracy', EZLN web page, available at www.ezln.org

Melucci, Alberto 1995, 'The process of Collective Identity', in Social Movements and Culture, ed. B. Klandermas, Minneapolis, University of Minnesota Press.

Ponce de Leon, Juana (ed.) 2001, Our Word is Our Weapon: selected writings, New York, Seven Stories Press.

Tarrow, Sidney 1998, Power in Movement: Social Movements and Contentious Politics, 
Cambridge University Press.

Tilly, Charles 1995, 'Contentious Repertoires in Great Britain 1758-1874', in Repertoires and Cycles of Collective Action, ed Mark Traugott, Durham, Duke University Press.

Tilly Charles and Tilly, Louise (eds.) 1981, Class Conflict and Collective Action, New York, Sage Publications.

Touraine, Alain 1981, The Voice and the Eye: An analysis of Social Movements. Cambridge University Press.

-1988, The Return of the Actor, Minneapolis, University of Minnesota Press, 1988.

_2001, 'The New Sociological Imagination', New School For Social Research, Graduate Faculty Working Paper, Spring 2001.

Virtual Communities of Vapatistas websites: virtual community of Zapatistas: http://www.chiapasmediaproject.org. Australia: http://www.geocities.com/CapitolHill/3849/zap.html. France: http://www.zapata.com/yabasta.php3; http://ouvaton.org/cspcl/. Italy: http://www.ipsnet.it/chiapas, http://www.ecn.org/ezln-it/ http://www.ecn.org/la.strada/ .In Ireland: http://flag.blackened.net/revolt/mexico.html . Netherlands: http://www.dds.nl/ noticias/prensa/zapata/. USA: http://www.geocities.com/CapitolHill/7083/, http://www.geocities.com/CapitolHill/1364/cpage1.htm, http://zapnet.rootmedia.org/, 